\title{
A Case Study of Code-Switching among Thai Waiters in a Cambridge, UK Restaurant
}

\author{
Nicola Prin \\ Instructor of Global Business Communication, Department of Arts, \\ International College, Burapha University, Chonburi, Thailand \\ nicol.pri7@gmail.comandnicola@go.buu.ac.th
}

\begin{abstract}
This study explores Thai bilingual speakers' code-switching in a formal work setting. Although code-switching may appear to be random, there is an underlying choice which speakers decide upon when switching between languages: Language proficiency, the initial speaker's language choice, the setting, and role relationships all contribute to these choices. This study investigates the factors contributing to code-switch decisions by participants within their specific work environment. The main findings show that adopting one language over the other depends on two main factors: first, the initial sequence of the interaction; second, the role relationship that the participants wish to maintain. This study has drawn upon the conversational approach and Auer's sequential analysis to collect and interpret data from ethno-graphic observations, questionnaires, and semi-structured interviews.
\end{abstract}

\section{Keywords}

Code-switching - bilingual - interaction - sequencing - relationship

A Bilingual speaker uses different languages for different purposes, in different contexts, with various degrees of proficiency to communicate with other interlocutors (Wei 2000). One aspect of bilingualism recognized throughout all definitions is the use of code-switching. Gumperz $(1982,59)$ defines codecode-switching as "the juxtaposition within the same speech exchange of 
passages of speech belonging to two different grammatical systems." More recent definitions have focused on conversation and social aspects. Tseng \& Cashman (2015) explain code-switching as essentially, bi- and multilingual speakers' use of more than one language or language variety within a single interaction or conversational turn.

Code-switching is often used as an umbrella term to include different language phenomena within the sentence and beyond. Code-mixing and language mixing are also well-known terms. (See Muysken 2000; Wei 2001). However, some researchers use the term code-switching for specific areas of language use. For example, Singh (1985) uses the term code-switching for inter-sentential switches and the term code-mixing for intra-sentential switching.

Code-switching can occur either intra-sententially, defined as an occurrence within a single sentence, constituent, or even word (Poplack 20o1), or inter-sententially, an event which Koban (2013) characterizes as a switch of language outside the sentence or clause level. This study focuses on inter-sentential switching and looks at the social elements that play a role in code-switching.

There is a wealth of research on inter-sentential code-switching, based on teaching and learning environments (Brice 2000; Martin-Jones 2003). This study hopes to add to the existing literature on inter-sentential code-switching by analyzing it in a specific work setting. This study examines how Thai bilingual speakers who work in a restaurant in Cambridge, UK, show a marked difference in their use of code-switching under different situations in their work setting. The aim is to see if an inter-sentential pattern determines code-switching by the participants from English to Thai, or Thai to English, such as the working relationship, social identity, and interaction context. The participants of this study are all Thai nationals who have lived in the UK for over five years. To get a clearer picture of how code-switching develops, the study is analyzed based upon Auer's sequential approach and the patterns of code-switching that he proposes. Three main questions are driving this research.

Research questions

- Do different situations initiate code-switching by bilingual speakers?

- Does the relationship between the bilingual participants influence code-switching?

- Does the initiating speaker influence the sequence of language use between different participants? 


\section{Defining Code-switching}

Various theories from different perspectives define code-switching. Many scholars recognize that code-switching goes beyond linguistic reasons and conveys a more social aspect to the choice of language used (Myers-Scotton 1995; Gafaranga 2007). Milroy $(1987,185)$ discusses code-switching from a social perspective and states, "bilingual speakers attribute different social values to different languages or codes." Blom and Gumperz (1986) characterize code-switching as a type of social strategy. Myers-Scotton (1995) extends this theory to include the notion that bilingual speakers use the process of code-switching to frame discourse and attach social meaning to the language, such as showing solidarity or power relations. Myers-Scotton $(2000,150)$ examines code-switching as a "type of skilled performance with specific communicative intent." Her study in East Africa observed the occurrences of language choice between Swahili and English. Myers-Scotton $(1993,132)$ emphasizes that there is one general motive for making marked choices; i.e. that the speakers engage in marked code-switching to indicate a range of emotions from anger to affection and negotiating outcomes ranging from demonstrations of authority to ethnic identity. Valdes-Fallis (1978) states that code-switching is neither random nor meaningless. Code-switching often conveys social information, such as relationship roles between the participants in the verbal interaction and expresses feelings of solidarity and intimacy. Since a different social value is associated with each language, the speaker's language use is determined by which language he/she deems more appropriate when interacting with varying interlocutors under different circumstances.

Mabule (2015) explains that code-switching is seen as functional in social conversations. However, it is considered marked code-switching because even if the relationship and socialization are relaxed, factors such as social status or age differences will have a role in language use. Romaine $(1995,122)$ looks at code-switching from a pragmatic level and states that "all linguistic choices are indexical of a variety of social relations, rights and obligations created and exist between participants in a conversation."

Fishman (2007) discusses an interactional sociolinguistic analysis of use and provides a framework for analyzing factors governing code-switching in a bilingual situation, group membership, situation, and topic. Fishman et al. (1971) undertook a study in a Puerto Rican community in New York City and identified five domains used in both languages: family, friendship, religion, employment, and education. These domains are abstract and refer to conversational activities within a specific time, setting, and role relationships. The argument put forward 
is that each of these domains holds different expectations as to which language is used by the bilingual speaker. However, the domains can be ill-defined, especially when examining code-switching from an inter-sentential approach. Auer (1995) suggests that instead of looking for an association between verbal activities and code-switching, the focus should be on which activities bilinguals switch from one language to another.

Sequential Approach

Auer's (1995) sequential approach sits within the framework of conversation analysis, which believes that the meaning of code-switching emerges out of the sequential development of conversational interaction. Auer's sequential approach was a reaction to the semantic approach theory, which distinguished between situational and metaphorical code-switching (Gumperz 1982). One main issue with this theory was that it was static and did not consider the fluid and active variables that go into language use within an active interactional context. Auer $(1984,4)$ states, "situational parameters do not determine language use by bilingual speakers; language is part of a complicated business of defining the situation." The complication is because the same cue can carry different meanings and receive a different interpretation depending on the situation and circumstance in which the exchange occurs between various participants. Tseng and Cashman (2015) support this theory and state that a single code-switched utterance can simultaneously fulfill multiple functions. Therefore, code-switching meanings are only understood in the interactional context. A central claim in Auer's model is that code-switching's pragmatic meaning depends on its sequential environment. A speaker may use a 'marked' (conscious) language choice depending on the following: who initiates the preceding utterance, topic, setting, and the relationship between the participants. The receiver then interprets this marked language in the next stage of the interaction sequence by interpreting the situation and understanding the speaker's intended meaning.

Unlike a macro-level socially focused approach, which links code-switching with 'the group identities of speakers involved, a conversation analysis approach believes that macro interpretations might rely too much on analysts' perceptions and purposes. In contrast, the sequential analysis focuses on the local, turn-byturn interpretation of code-switching meaning, which develops and changes as the conversation is evolving (Wei and Moyer 1998, 170). Each situation in which the interaction occurs will have its own unique cues and interpretations. 
Many researchers see the benefit of using a sequential approach to analyze code-switching. Jorgensen (1998) looked at language and power relationships amongst children in a Danish-Turkish environment. Similarly, a study undertaken by Wei and Milroy (1995) looked at code-switching in a Chinese community in the UK. They used a conversational-style sequential approach to bilingual code-switching. Their research revealed that the language used represented social symbolism, defined as 'we code.' Often the speaker is aware of the preferred language. For example, if the speaker code-switches to a different language, it is often to draw attention to a part of the conversation to be interpreted differently from the interaction. Wei and Milroy $(1995,282)$ stated that using code-switching of such contrastive language choices by different speakers in consecutive turns is only used in a sequential approach within a conversational analysis framework.

\subsection{Code-switching in a Formal Setting}

There are a few studies that focus on code-switching in a formal setting, such as a workplace. Socarraz-Novoa (2015) observed bilingual English and Spanish speakers in a formal university workplace. They discovered three main reasons that code-switching occurred: face-saving, expression of raw emotion, and compartmentalization of work and private life. The findings showed a distinctly marked language use between English for work-related issues and Spanish for social issues. Mondada (2007) revealed that code-switching is a powerful resource in the workplace for building work activities amongst participants. Mondada $(2007,315)$ says that "This order is achieved by specific ways of doing things, that are locally anchored in the participants' identities and at the same time elaborate them."

\subsection{Code-switching among Thai Speakers}

Kongkerd (2015) researched code-switching on Facebook by Thai users. The findings indicate that code-switching to English can express politeness and respect, convey exact meanings and feelings, and express Thai identity or group membership. Promnath and Tayjasanant (2016) examined the characteristics, types, and functions of code-switching in conversations between teachers and students in two ESP classes at a university in Bangkok. The research looked at both intra-sentential and inter-sentential switching. The results state that formal code-switching was used as a pedagogical interaction to serve the course's goals. Conversational code-switching was used for socialization, enabling teachers and students to organize and create a good classroom atmosphere. Both studies highlight the use of code-switching to include group identity and formal and informal context for code-switching. 
This research is primarily a qualitative study that produces descriptive data in the form of words. Dornyei $(2007,19)$ states, "qualitative data...usually involves recorded spoken data (for example, interview data) that is transcribed to textual form as well as written reports." Researchers in code-switching tend to prefer certain types of data. For instance, Myers-Scotton (2006) has argued that only naturalistic data can inform code-switching research since it is the only type of data in everyday situations. This study uses an ethnographic approach for real-time observation of different interactions amongst different participants. The data collection includes various techniques, including observation, questionnaires, and semi-structured interviews. Using a combination of collection methods helps to ensure the research is trustworthy and credible.

To ensure that data collected from observations came from different situations and conditions at the restaurant, they took place over two weeks at varying times of the day. Participants completed a questionnaire which gathered data on their perception and knowledge of their language use and code-switching. Semi-structured interviews probed for more in-depth information about the participant's work and social relationship and identity using Thai and English languages. The data collected from the semi-structured interviews and questionnaire was compared to the 'real-time' exchanges observed at the restaurant. This comparison helped identify if the participant's perception and belief about their language use at work took place in real-time situations. It was important for the researcher to administer the data collection techniques in a specific order: first observation, next, questionnaire, and semi-structured interviews. The order helped to minimize any unintentional influence of the findings. For example, observations were conducted before the questionnaire and semi-structured interviews to minimize any pre-identified patterns. The questionnaire data helped to ask follow-up questions in the interviews to minimize any participant's answers. The analysis from all the data yielded some interesting results regarding code-switching within a work setting.

\section{Participants}

The participants in this study are all Thai nationals, who are bilingual speakers of Thai and English. The participants have all lived in the UK between $5^{-10}$ years. Their English proficiency is high, as they have experience studying in a UK school and college. The participants are male between the ages of 22 
and 25. All participants indicated and demonstrated confidence and capability to use English and self-rated themselves as at high intermediate levels. For this study, a letter code is assigned to each participant shown in table 1 below, unless otherwise stated.

TABLE 1 Participants of study

\begin{tabular}{lll}
\hline Participant & Code & Language \\
\hline Interviewer & $\mathrm{I}$ & English speaker \\
Customer/s & $\mathrm{C}$ & English speakers \\
Waiter 1 & $\mathrm{~W}_{1}$ & Bilingual speakers \\
Waiter 2 & $\mathrm{~W}_{2}$ & Bilingual speaker \\
Supervisor & $\mathrm{S}$ & Bilingual speaker \\
\hline
\end{tabular}

The following data represents feedback from the questionnaire that the Thai bilingual participants completed. Questions 1 and 2 are ranked [1-5], which represents self-assessment of language ability. Table 2 below shows the participants responses for questions 1 and 2, ranking from 1 being the lowest and 5 the highest.

The questionnaire data revealed that the participants indicated their English proficiency levels for Q1: W1 [4], S, and W2 at the highest rank of [5]. All Thai participants live in the UK and use English in everyday situations and for academic purposes. For Q2, the participants stated that they are comfortable interacting in English and do not have to revert to Thai for proficiency. All participants selected a score of [5]. From this information, we can discern that the participants can conduct all interactions using English. The next set of questions $3-5$ uses a ranking score of $[1-5]$, representing frequency. The

TABLE 2 Questionnaire responses [Q1-Q2]

\begin{tabular}{|c|c|c|c|c|}
\hline Rank (Ability) & \multirow{2}{*}{\multicolumn{2}{|c|}{$\mathrm{W} \mathrm{W}_{2}$}} & \multirow[t]{2}{*}{ Mean } & \multirow{2}{*}{ S.Dev } \\
\hline $\begin{array}{l}1=\text { very poor; } 2=\text { poor; } 3=\text { average; } 4=\text { good; } \\
5=\text { =very good }\end{array}$ & & & & \\
\hline 1 What le & 4 & 5 & 4.66 & 0.57 \\
\hline 2 Are you confident \& comfortable using English? & 5 & 5 & 5.00 & 0.00 \\
\hline
\end{tabular}


TABLE 3 Questionnaire responses [Q3-Q5]

Rank (Frequency)

W1 W2 S Mean S.Dev

1=never; 2 =rarely; 3 =sometimes; 4 =very often;

5 =always

3 How often do you speak English outside of work?

$\begin{array}{lllll}3 & 5 & 4 & 4.00 & 1.00\end{array}$

4 How often do you speak (in English) to each other

$\begin{array}{lllll}4 & 4 & 4 & 4.00 & 0.00\end{array}$

in the work environment on work-related issues?

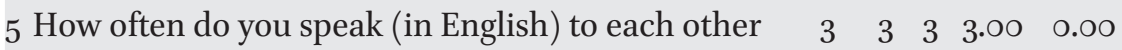

in the work environment on non-work-related

issues?

following table 3, shows the participants feedback on the amount of English they speaking during work hours and in more social situations.

Q3 indicated that Thai was the more popular language spoken outside of work amongst Thai friends and family, but English was high due to high interaction with non-Thai speakers in everyday life in the UK. W1 had the lowest use at a score of [3]. In follow-up interviews, W1 was the only participant not in university, so English outside of work scored lower than the other participants because he did not need to communicate and interact in English with class friends and professors daily.

Q4. Participants rated [4] for English at work, for work-related issues but indicated in Q5 a lower rating of [3] for non-work interactions while at work. One reason for the frequency of English used at work is interaction with customers, who are primarily English speakers or use English as the lingua franca. However, the observations also revealed code-switching taking place amongst the participants, even when there was no customer interaction. Observation data reveal that the code-switch greatly depended on the initial sequence of discourse by participants. Moreover, the interviews revealed that the participants used a marked choice, either English or Thai, depending on the specific situation and the established relationship they were trying to maintain in each exchange.

The following data represents questions 6-9 of the questionnaire. A numeric code represents each response for data analysis.

For Q6, all participants responded with [yes] to comfort in speaking English at work. A similar question was asked for Q7 but asked about comfort speaking in Thai when at work. The results show W1 indicating [no], W2 [yes], while S ranked a response of [neutral]. As we see, there is a disparity between each participant on this question. The interviews revealed that Thai was used mainly 


\begin{tabular}{|c|c|c|c|c|c|c|}
\hline & $\mathrm{k}$ (Comfort) Yes $=1 ; \mathrm{No}=2 ; \mathrm{Neutral}=3$ & W1 & $\mathbf{W}_{2}$ & S & Mean & S.Dev \\
\hline 6 & $\begin{array}{l}\text { Do you feel comfortable speaking } \\
\text { English to each other when at } \\
\text { work? }\end{array}$ & Yes & Yes & Yes & 1.00 & 0.00 \\
\hline 7 & $\begin{array}{l}\text { Do you feel comfortable speaking } \\
\text { in Thai, to each other, when at } \\
\text { work? }\end{array}$ & No & Yes & Neutral & 2.00 & 1.00 \\
\hline 8 & $\begin{array}{l}\text { Do you feel comfortable speaking } \\
\text { English in front of customers? }\end{array}$ & Yes & Yes & Yes & 1.00 & 0.00 \\
\hline 9 & $\begin{array}{l}\text { Do you feel comfortable speaking } \\
\text { Thai, in-front of customers? }\end{array}$ & No & No & Neutral & 2.33 & 0.57 \\
\hline
\end{tabular}

for social interactions and English for formal interactions. However, this can depend on the conversation. For example, if S used Thai, then $\mathrm{W}_{1}$ and $\mathrm{W}_{2}$ felt more comfortable responding in Thai, indicating the interaction's initial sequence has a role in the code-switch. It was interesting to note that $S$, who rated a [neutral] position, felt that code-switching between Thai and English depended on the relationship he wanted to portray to the other participants, either as a supervisor or as a friend, during work hours.

Q8 yielded expected results with all participants indicating positive [yes] responses. Q9 showed a slight difference between $\mathrm{W}_{1}$ and $\mathrm{W}_{2}$ [no] results with that of [S] who selected [neutral]. Further feedback from interviews ascertained that the use of Thai was for specific situations. This point is discussed further in the following section.

\section{8}

\section{Interviews}

Each interview was on a one-on-one basis to ensure that each participant did not influence each other or follow each other's responses. The interviews were semi-structured based upon the questionnaire responses. Further discussions obtained detailed answers. The participants' feedback is under headings [Feedback 1-8]; this helps the reader see the connection between the questionnaire, interviews, and observation data. The question was asked to the participants if they considered themselves bilingual speakers. The responses were yes, although labeling themselves as bilingual had not been a previous consideration. 
Feedback 1

W1: "I guess I just speak Thai and English."

W2: "I think I am a Thai speaker who can speak English."

S: "Ifeel comfortable with Thai and English, so I guess I am a bilingual."

Further discussion confirmed the responses to $\mathrm{Q}_{2}$ of the questionnaire that participants felt confident and comfortable using English.

Feedback 2

W1: "I don't think about it. I have been using English for such a long time."

W2: "I sometimes think my English is stronger than my Thai because I use it every day, and living in the UK, there is not a choice."

S: $\quad$ "English is the language we hear and use all the time because we are in the UK. Thai is used when we are together or with family, as no one else can speak it."

All participants stated that Thai was the preferred language for social interactions. However, there was an acknowledgment that it depends on the situation. For example, outside of work was more accepted than at work.

Feedback 3

W1: "Using Thai is just natural when we are chatting about stuff, I think it is just a habit. But I use English more when I am at work because there are always customers or people that can't speak Thai around, so it may not be OK."

W2: "It kind of depends on what we are talking about. When we are talking about ourselves and friends, we say it in Thai. You know, when we are joking around. When our supervisor is around, we always talk in English. I think it sounds better, as he is our boss. But sometimes, if he jokes around with us, he will speak Thai as well."

S: $\quad$ "I mainly use English, sometimes I use Thai, like at break times and before we open to customers."

These responses show that each situation is not the same, and factors such as customers, topic, location, and relationship all contribute to the language choice made. For example, $\mathrm{W}_{2}$ explains that the relationship with $\mathrm{S}$ is formal and social, so, depending on the situation and relationship established for that specific conversation, either Thai or English may be used. As Mondada (2007) explains, code-switching is locally anchored in the participants' identities. 
When asked about the preferred language used to discuss work-related issues, the responses were as follows.

Feedback 4

W1: "I use English when I am passing on information from a customer. Like, if a customer asks me for something from the bar, I usually then will ask whoever is working at the bar in English."

W2: "I don't know, sometimes I just say it in Thai and other times in English. It is just the way it comes out. If I hear English, I speak in English, if I hear Thai, I speak in Thai."

S: "Inearly always use English, as I must work between customers and staff. It sounds better, and everyone can understand what is going on."

These responses illustrate that the participants are aware of what they deem appropriate talk in a work situation. Depending on language use, for the initial conversation, the same language is continued for the interaction. Interestingly, the observations show that if the initial sequence between $\mathrm{C} / \mathrm{W}_{1}$ is in English, when $W_{1}$ moves away and continues the sequence with W2 (away from the customer), the conversation continues in English with no switch to Thai. However, it was also noticed that code-switching is sometimes used, especially by $S$, when having to repeat an instruction. For example, the initial sequence between $\mathrm{C} / \mathrm{S}$ is in English; S/W1 continues in English [nil response], then S/W1 code-switches to Thai. This point is discussed further in section 4.4.3.

When participants were asked about using Thai at work in front of customers for work-related issues, they all indicated that they did not think this was appropriate.

Feedback 5

W1: "No, because it is not OK, as the customers might get upset."

W2: "I think it would be confusing to keep changing from English to Thai, so if we speak with a customer in English, then it is easier to keep using English between us."

S: $\quad$ "It is not professional to talk in Thai when there are customers there. They may not be oK with it and get confused about what we are saying. Also, if I say something in Thai, and it is a mistake, how can the customer know?"

When asked about interactions with each other when no customers were present, the replies indicate that English is preferred when talking about work 
issues, giving information, and showing urgency. Also, English is regarded as formal and helps to maintain role relationships at work.

Feedback 6

W1: "I don't know, but I guess I use English at work because [name] S does, he is our boss."

W2: "Usually, when we work, we have to find things for the customer, who ask us in English. So, it is better and easier to ask my workmate in English, as I don't need to think about changing language."

S: $\quad$ "Using English is more professional, and my team can understand what I want from them easily."

The participants perceive English as a more formal and appropriate language to use when at work. This language use may be a reason for S to state that 'English is professional. Also, by using English, $\mathrm{S}$ can establish a role relationship with W1 and W2. For example, if he were to use Thai, they may interpret it as non-urgent because it is attached to social interaction. The response from Wi supports this, as he acknowledges the relationship between himself and $S$ while at work.

One interesting finding emerged when asked about the use of Thai by non-Thai speakers. For example, if a customer (non-Thai) spoke in Thai, how would the participants respond? All participants indicated a reluctance to accommodate the speaker's use of Thai. Although there was no observation of this exchange, the participants discussed that they would feel uncomfortable for several reasons.

Feedback 7

W1: "I would be surprised and not expecting it, so I do not think I would even realize at first they were speaking Thai. I am not sure about it."

W2: "I think I should speak in English because I might not understand their Thai accent, and I want to make sure I get the order right - so repeating in English is better."

S: "I think I would use English, as this is better at work to make sure that everything is correct."

The feedback indicates that in their work setting, the preference to use English for formal exchanges still holds, even when the initiating non-Thai speaker uses Thai. The main reason for this is understanding, but there appears to be a strong identity attached to Thai use. A follow-on question, if the customer were Thai and made a request in Thai, how would you respond? The feedback was an emphatic affirmative by all participants; they would respond in Thai. When pushed further on this and reminded that the interaction was still 
work-related, the participants did not have a clear answer as to why they would respond in Thai and not English.

Feedback 8

W1: "I'm not sure actually, maybe because it would be natural to do this."

W2: "I just do it without thinking."

S: "I don't want to be disrespectful."

There was no observation of this interaction, and therefore, if such were to occur in a real-life situation, it is unknown what the participants would say in reflection. However, their answers support the idea that language plays a significant role in in-group identity.

All participants acknowledged the language used by the initiating speaker in the interaction sequence is the preferred language for further dialog between interlocutors within a work environment; this was evident in the observations. If the initial sequencing was in English, all subsequent exchanges continued using English. In other words, the speaker is making a 'marked language use.' The only indication that code-switching would occur from the initial sequence is if an English customer used Thai, in which case, the participants stated that they would reply in English [feedback 7]. The only time code-switching took place within a conversation is if the initial request got a nil response, as observed with S to W1 [observation 3], and between $\mathrm{W}_{1}$ and $\mathrm{W}_{2}$ in non-workrelated interactions [observation 2].

Hall (2012) states that the identity that becomes significant depends on the situation, our goals - what we want to achieve from the exchange, and the identities and role relationships. In the participants' case, they acknowledged that their relationship changed at work, as they held different responsibilities and positions and interacted with customers. Using English helps shape their relationship with each other in the workplace, rather than using Thai, which they associate with a social relationship.

Although the participants acknowledged they used English for work-related purposes, they underestimated the regularity of English they used between themselves in contrast to the observations' findings. Interestingly, all participants indicated that when a customer initiated the exchange's initial sequence, the following sequence of interaction amongst themselves continued in English, even when the customer was no longer in the exchange. This exchange was observed on numerous occasions during the observations and under different conditions, and fits into Auer's model, suggesting that the receiver's language to continue the exchange depends on the initial sequence and how the receiver interprets this. When asked why the participants thought this occurred, 
the responses were varied. All participants recognized that the language they used reflected their social identity in each interaction and situation. However, this was not overtly evident to the participants, but they connected how their language helped identify themselves in different exchanges during discussions. Sometimes, done explicitly, for example, $\mathrm{S}$ noted that it was a conscious choice to use English in exchanges between either W1 or W2 when requesting or giving work orders, as this helped to reaffirm his position as supervisor. Sometimes it was implicit. For example, the participants did not recognize that they often revert to Thai when engaging in social conversation, even if they had just been interacting using English for work-related exchanges. During observations, as discussed in section 4.3, [observation 2], this was evident when the restaurant was quiet with few customers present. The participants appeared relaxed, and the conversation turned to non-work-related topics.

\section{9}

\section{Observations}

All observations were conducted in real-time, across two weeks at various times of the day. The interactions were analyzed as authentic exchanges of communication between the participants and between participants and customers. For this study, three out of the five observations were analyzed. The data collected from these observations shows similar findings from all observations.

\subsection{Observation 1}

This observation took place on a Wednesday evening. The restaurant was moderately busy, with approximately $8 \circ \%$ occupancy. All participants were present. W1 greeted the customers in English (4 persons) and showed them to a table. All greetings and initial interaction were conducted in English as expected due to language knowledge on the customers' part. W1 offered a menu (during this period, little or no verbal exchange took place, except for the giving of the menu). W1 returned to the table and asked what drinks the customers would like. The customers gave their requests; $\mathrm{W}_{1}$ acknowledged their requests and then walked over to the bar area where $\mathrm{W}_{2}$ was positioned and conveyed the request to $\mathrm{W}_{2}$ in English. The sequence was as follows: [W1/C, C/W1, $\left.\mathrm{W}_{1} / \mathrm{W}_{2}\right]$. This interaction shows that the initial language in the sequence continues for the whole situation, even between $\mathrm{W}_{1}$ and $\mathrm{W}_{2}$ when no customers were present. This conversation sequence follows Auer's model, which states that a speaker may use a marked choice depending on the initiating utterance. Both participants indicated in [question 9] of the questionnaire and [feedback 4] from the interviews that they are consciously deciding on the language they 
use due to what they deem appropriate in their work setting and the specific interaction context.

\subsection{Observation 2}

Observation 2 took place during a Thursday lunchtime. The restaurant was quiet, with approximately $30 \%$ occupancy. On this occasion, S was not present, and $W_{1}$ was covering for $S_{\text {. W }}$ initiated a direction to W2 in English, asking to check on the status of the order for table 4 that was occupied by two customers. W2 showed acknowledgment by repeating the direction in English and proceeded with carrying out this request. The conversation sequence was [ $\mathrm{W}_{1} /$ $\left.\mathrm{W}_{2}, \mathrm{~W}_{2} / \mathrm{W}_{1}\right]$. This exchange was done in the customers' presence and followed Auer's model's conventions, considering the participants and setting. The participants discussed this exchange in interviews [feedback 5 ] and reviewed in [question 8] of the questionnaire. Where participants acknowledged, they felt more comfortable using English in front of customers.

However, it was also observed later in the afternoon, when there were only two tables occupied, that when $\mathrm{W}_{1}$ and $\mathrm{W}_{2}$ were not interacting with customers, they conversed in Thai. The conversation was relaxed and appeared to be on a general, non-work-related topic. This was the only instance during observations where the restaurant was very quiet, low occupancy of customers, and $\mathrm{S}$ was not present. It was unclear who initiated the interaction in Thai, but it does show that code-switching to Thai was under a unique situation. It is unclear whether, if $\mathrm{S}$ was present, $\mathrm{W}_{1}$ and $\mathrm{W}_{2}$ would use Thai, due to the established work role relationship. However, due to the conversation being social talk and not work-related, there is a possibility that $\mathrm{S}$ would also have used Thai, as indicated in his interview [feedback 3].

Moreover, the environment during this time was extremely quiet and relaxed, with minimal customer interactions. This instance highlights that it is important to look at each interaction as a localized event when researching code-switching with its specific cue. As stated by Auer (1984), bilingual speakers' use of language depends on how they define the situation.

\subsection{Observation 3}

Observation 3 was conducted at the restaurant's busiest time on a Saturday evening, with full occupancy of customers and customers waiting for an available table. All participants were present. $S$ took an order from 4 people; $S$ repeated the order back to the customers. The sequence was $[S / C, C / S, S / C]$. This exchange was in English. S called to $W_{1}$ to help with the drinks order. $S$ gave the instructions to $\mathrm{W}_{1}$ (in-front of the customers) using English. However, there was a nil response. 
Interestingly, $S$ then spoke in Thai to repeat the request. W1 responded by using a Thai response khrap to acknowledge $S$. The pattern of this sequence was $\left[\mathrm{S} / \mathrm{W}_{1}, \mathrm{~W}_{1} / \mathrm{S}\right]$. The initial request performed by $\mathrm{S}_{\mathrm{S}} \mathrm{W}_{1}$ used a marked code of English, which fits with the relationship role of Supervisor and Waiter, and the use of English for work-related interactions. However, when there was nil response to the request, $\mathrm{S}$ made a marked code-switch to Thai. This switch was for two reasons, first, to make sure W1 understood the request and had not missed the cue of the importance of what was asked and gain a more favorable response by using Thai, as it is associated with social exchanges between the participants. It was unclear whether, if the request was repeated in English, the same response would have occurred, or if the initial nil acknowledgment and nil action were due to other factors, such as not hearing the request, due to noise or other distractions. However, once the specific interaction had finished, further interactions between the same participants reverted to English. This exchange seems to imply that a marked code-switch reaffirms the role relationships and social identity in which the participants wish to portray themselves within the work setting.

\subsection{Summary of Observations}

The observations showed that only when the restaurant was quiet, with low customer occupancy, did the participants talk in Thai. They showed that English is the language most used in the participants' work setting, especially during busy periods with high occupancy of customers. English use could be due to various reasons, such as a more significant number of interaction occurrences between the participants and customers and more work-related conversations. When a customer initiated the initial sequencing of interaction, the exchange that followed between the participants was, for the most part, conducted in English. On occasion, the Thai word 'khrap' was used to show acknowledgment of a request, but there was a code-switch back to English when further conversation occurred. This language choice indicates that the role relationship is maintained between speaker and interlocutor by using English, which has established the acknowledgment of participants that English is perceived to be the more formal language. When the participants interacted, without customer involvement, Thai and English were used depending on the situation. However, in more than $50 \%$ of this type of interaction, during observations, the participants used English. This fits into the response given by W1 during the interview, who stated:

W1: "I sometimes use Thai when I don't want a customer to know what I am talking about, but not often." 
In this instance, Thai is used as a 'marked language' to exclude the Englishspeaking customer from the exchange. This was also noted by W2:

W2: "I speak Thai when we are joking around, but it's not really right for work."

In this instance, there is a noticeable distinction made between the use of Thai for informal talk and English as the language for work.

This study concludes that code-switching is used among the participants to identify formal and social interactions in specific situations and follow the initial sequence's language. It determines that each case has its own unique set of cues and interpretations and that it is not easy to categorise code-switching into typologies because multiple factors will influence the language used during a conversation. Firstly, participants either implicitly or explicitly acknowledge that their code-switching marks their identity while at work, whether with customers or among themselves. This marked identity helps to establish relationship roles between formal and social conversations. The role relationship is especially evident with interactions between $S$ and either $W_{1}$ or $W_{2}$. W1 and W2 use English with S while at work. However, if $S$ initiated a conversation in Thai, then W1 and W2 would code-switch to Thai. This helps W1 and W2 to establish whether $\mathrm{S}$ is conversing formally as their boss or engaging in social conversation as a friend.

For $\mathrm{W}_{1}$ and $\mathrm{W}_{2}$, there are more code-switching occurrences with each other when not in customers' presence. There are more informal conversations that often start in English but quickly revert to Thai. Observed in every instance was that once a work-related issue occurs, the code-switch to English is automatic, supporting the data that the participants use a marked switch of language between work and social life.

Further research might look in more detail at the cultural influences, including in/out-group membership, attitude, and identity in such an environment. It would also be interesting to see the participants' factors to code-switch specific to these participants and the work environment. If repeated with different bilingual speakers (different languages), would the same factors influence language use? 


\section{References}

Auer, Peter. 1984. Bilingual Conversation. Amsterdam/Philadelphia: John Benjamins Publishing. doi.org/10.1075/pb.v.8.

Auer, Peter. 1995. "The Pragmatics of Code-Switching: A Sequential Approach." In One Speaker, Two Languages, edited by Lesley Milroy, Pieter Muysken, 115-135. Cambridge: Cambridge University Press. doi.org/10.1017/CBO9780511620867.006.

Blom, Jan Petter, and John Gumperz. 1986. "Social Meaning in Linguistic Structure: Code-Switching in Norway." In Directions in Sociolinguistics: The Ethnography of Communication, edited by John Gumperz and Dell Hymes, 409. New York: Blackwell.

Brice, Alejandro. 20oo. "Code-Switching and Code Mixing in the EsL Classroom: A Study of Pragmatic and Syntactic Features." International Journal of SpeechLanguage Pathology 2 (1): 19-28. doi.org/10.3109/144170400o8996783.

Dornyei, Zollan. 2007. Research Methods in Applied Linguistics Quantitative, Qualitative, and Mixed Methodologies. Oxford: Oxford University Press.

Fishman, Joshua, Robert Cooper, and Roxana Ma Newman. 1971. Bilingualism in the Barrio. Bloomington: Indiana University Press.

Fishman, Joshua. 2007. "Who Speaks What Language to Whom and When?" In The Bilingualism Reader, edited by Li Wei, 55-70. New York: Routledge.

Gafaranga, Joseph. 2007. Talk in Two Languages. Basingstoke: Palgrave Macmillan.

Gumperz, John. J. 1982. Discourse Strategies, Studies in International Sociolinguistics. Cambridge: Cambridge University Press.

Hall, Joan Kelly. 2012. Teaching and Researching: Language and Culture 2. London: Routledge. doi.org/10.4324/9781315833712.

Jorgensen, J. Normann.1998. "Children's Acquisition of Code-Switching for Power Wielding." In Code-Switching in Conversation, edited by Peter Auer, 237- $25^{8}$. London: Routledge. doi.org/10.4324/9780203017883.

Koban, Didem. 2013. "Intra-Sentential and Inter-Sentential Code-Switching in TurkishEnglish Bilinguals in New York City, US.” Procedia - Social and Behavioral Sciences 70: 1174 - 1179. doi/10.1016/j.sbspro.2013.01.173.

Kongkerd, Wilaiporn. 2015. "Code-Switching and Code Mixing in Facebook Conversations in English among Thai Users." Bangkok University Executive Journal 1(35): 131. https://www.bu.ac.th/knowledgecenter/executive_journal/jan_june_15/ pdf/aw13.pdf.

Mabule, Dorah R. 2015. "What Is This? Is It Code Switching, Code Mixing, or Language Alternating?" Journal of Educational and Social Research 5 (1). doi/10.5901/jesr.2015. v5nip339.

Martin-Jones, Marylin. 2003. "Teaching and Learning Bilingually: Towards an Agenda for Qualitative Classroom-Based Research." https://www.researchgate.net/ 
publication/241075608_teaching_and_learning_bilingually_towards_an_agenda_ for_qualitative_classroom-based_research.

Milroy, Lesley. 1987. Observing \& Analyzing Natural Language: A Critical Account of Sociolinguistic Method. Oxford: Blackwell Publishers.

Mondada, Lorenza. 2007. "Bilingualism and the Analysis of Talk at Work: CodeSwitching as a Resource for the Organization of Action and Interaction." In Bilingualism. A Social Approach, edited by Michal Heller. Basingstoke: Macmillan Publishing. doi.org/10.1057/9780230596047_14.

Muysken, Pieter. 200o. Bilingual Speech. A Typology of Code-Mixing. Cambridge: Cambridge University Press.

Myers-Scotton, Carol. 1993. Social Motivations for Codeswitching. Evidence from Africa. Oxford: Clarendon Press.

Myers-Scotton, Carol. 1995. "The Rise of Code-Switching as a Research Topic." In Social Motivations for Codeswitching: Evidence from Africa. Oxford: Clarendon Press.

Myers-Scotton, Carol, 20oo. "Code-switching as Indexical of Social Negotiations." In The Bilingualism Reader, edited by Lei Wei, 137-165 London: Routledge.

Myers-Scotton, Carol. 20o6. "Natural Code-Switching Knocks on the Laboratory Door." Bilingualism: Language and Cognition 9: 203-212. doi/10.1017/S1366728906oo2549.

Poplack, Shana. 2001. "Code-Switching: Linguistics." In The International Encyclopedia of the Social and Behavioral Sciences, edited by Niel Smelser and Paul Baltes, 20622065, Elsevier Science Ltd. doi/10.1016/Bo-o8-043076-7/o3031-X.

Promnath, Korawan, and Chamaipak Tayjasaant. 2016. "English-Thai Code-Switching of Teachers in ESP Classes.” PASAA (51) 97-126. https://files.eric.ed.gov/fulltext/ EJ1112243.pdf.

Romaine, Suzanne. 1995. Bilingualism. Oxford: Blackwell Publishers Ltd.

Singh, Rajenda. 1985. "Grammatical Constraints on Code-Mixing: Evidence from Hindi-English." Canadian Journal of Linguistics 30 (1): 33-46. Cambridge University Press. doi/10.1017/Sooo841310oo10677.

Socarraz-Novoa, Alejandra. 2015. "Code-Switching in a Multilingual Workplace." The Journal of Undergraduate Ethnography 5 (1). file://C:/Users/admin/ Downloads/8261-13968-1-SM.pdf.

Tseng, Amelia, and Holly Cashman. 2015. Code-Switching Pragmatics. The Encyclopedia of Applied Linguistics. John Wiley \& Sons, Ltd. doi.org/10.1002/9781405198431. wbeal1458.

Valdes-Fallis, Guadalupe. 1978. "Code-Switching and the Classroom Teacher." Language in Education: Theory and Practice 4: 33-34. https://files.eric.ed.gov/fulltext/ ED153506.pdf.

Wei, Li, and Lesley Milroy. 1995. "Conversational Code-Switching in a Chinese Community in Britain. A Sequential Analysis." Journal of Pragmatics 23 (3): 
281-299. Elsevier. file://C:/Users/admin/Downloads/Conversational_code_ switching_in_a_Chine.pdf.

Wei, Li, and Melissa Moyer. 1998. The Blackwell Guide to Research Methods in Bilingualism and Multilingualism. Blackwell Publishing. doi/10.1002/9781444301120.

Wei, Li. 200o. "Dimensions of Bilingualism." The Bilingualism Reader, 3-25. New York: Routledge. https://vulms.vu.edu.pk/Courses/ENG512/Downloads/[Li_Wei]_The_ Bilingualism_Reader(BookFi).pdf.

Wei, Longxing. 2001. "Lemma Congruence Checking Between Languages as an Organizing Principle in Intrasentential Codeswitching." International Journal of Bilingualism 5 (2): 153-174. doi/10.1177/13670069010050020201. 